\title{
ESTADO DA ARTE:
}

\section{uma forma especial de educação médica continuada.}

A missão fundamental dos Arquivos Brasileiros de Cardiologia é a de incentivar e divulgar a produção científica cardiológica nacional. Para este fim tem no seu processo de seleção, da mesma forma que os periódicos científicos mais conceituados, a prioridade para os artigos originais revisados pelos pares. Esta filosofia editorial, presente nas comunidades científicas mais produtivas, garante a presença dos Arquivos no Index Medicus e a sua liderança na América do Sul.

Uma missão também importante de nossa revista, atualmente com cinqüenta anos de existência, é a de contribuir com a educação médica continuada, com a conseqüente melhora do desempenho e comportamento médico. Embora este fenômeno seja complexo e de difícil quantificação, alguns indicadores consideram as revistas médicas como as maiores responsáveis por este efeito, detectado principalmente em especialidades desenvolvidas como a nossa. Dados obtidos em nosso meio, durante pesquisa realizada pelos "Arquivos" no XIII Congresso Mundial de Cardiologia, demonstraram que a nossa revista é importante na formação do cardiologista brasileiro.

Atentos às linhas editoriais educativas de grande eficácia para a nossa especialidade, reservamos neste ano um precioso espaço de nossa revista para abrigar de uma forma programada temas de grande abrangência, relacionados à educação médica continuada. Assim, paralelamente à jáiniciada série de "medicina baseada em evidências", estamos implantando nesta edição um espaço para a abordagem ampla, concisa e sistemática dos grandes tópicos da cardiologia.

Apesar de temas gerais das especialidades médicas estarem bem compartimentados em compêndios e livros, a organização e formatação dos mesmos associam-se a uma desatualização de pelo menos um a dois anos. Além disso, estes temas são amplamente questionados anualmente pelos congressos nacionais e internacionais, e modificados por um grande volume de publicações nesse mesmo período.

A estrutura da nossa Sociedade, que comporta departamentos e grupos de estudos de praticamente todas as subespecialidades cardiológicas, congrega pesquisadores do mais alto nível, que se relacionam e contribuem continuamente com a ciência em nível nacional e internacional. Estes profissionais que acompanham de uma forma entusiástica e crítica os avanços da ciência e tecnologia foram convocados pelos Arquivos para contribuir com este novo espaço de nossa Revista.

A profissão médica é uma arte que administra o conhecimento científico. A série "O estado da ARTE" que tem o seu primeiro artigo neste número, procurará, com o auxílio de um profissional de experiência inquestionável, delinear de uma forma concisa e fotográfica, o estado atual do conhecimento de um assunto de máxima relevância cardiológica.

Os Arquivos Brasileiros de Cardiologia, adaptando-se continuamente às transformações decorrentes da globalização, pretendem demonstrar com o "estado da ARTE" que, apesar dos sofisticados recursos de comunicação do fim do milênio, uma revista conceituada é ainda uma forma potente e abrangente para o acesso às informações atualizadas de nossa especialidade, contribuindo assim com a excelência de nossa profissão arte.

Angelo A. V. de Paola

Marcia Barbosa 